\title{
0 retorno ao documento: reaproximações entre a Ciência da Informação e a Documentação
}

Gabriela Fernanda Ribeiro Rodrigues ${ }^{I}$ http://orcid.org/0000-0001-9924-5435

Dulce Maria Baptista II

http://orcid.org/0000-0003-0063-214X

I Universidade de Brasília, DF, Brasil.

Mestra em Ciência da Informação do Programa de Pós Graduação

em Ciência da Informação da Faculdade de Ciência da Informação - UnB.

II Universidade de Brasília, DF, Brasil.

Professora Doutora Colaboradora do Programa de Pós Graduação

em Ciência da Informação da Faculdade de Ciência da Informação - UnB.

http://dx.doi.org/10.1590/1981-5344/3558

Por um período os estudos sobre documento na Ciência da Informação foram deixados de lado em favor dos estudos sobre a informação. Nas últimas décadas os pensamentos de Paul Otlet e Suzanne Briet sobre o conceito de documento foram resgatados e inseridos na Ciência da Informação. Este estudo analisa a reaproximação da Documentação e da Ciência da Informação, na perspectiva do movimento Neodocumentalista. Foi realizada uma pesquisa bibliográfica, apresentando um breve histórico da Documentação e suas relações com a Ciência da Informação. Após revisão de literatura, expõe alguns fatos sobre a formação do novo movimento, nomeado como movimento neodocumentalista ou neo documentação. Conclui ser oportuna a discussão sobre 
documento e informação para possibilitar uma melhor compreensão sobre ambos os conceitos.

Palavras-chave: Documentação. Neodocumentação. Conceito de Documento.

\section{The return to the document: rapprochement between Information Science and Documentation}

For a while, the studies about document in Information Science was left aside on behalf of the studies about information. In last decades, Paul Otlet's and Suzanne Briet's thoughts have been rescued and inserted in Information Science. This paper analyses the rapprochement between Documentation and Information Science in the perspective of Neodocumentalist moviment. A bibliographic research was realized, by presenting a brief history of Documentation and its relation with Information Science. It was realized a review of literature and some facts were exposed about the formation of the new movement, named as neodocumentalist movement or neodocumentation. It concludes the debate about document and information is important for a better understanding about both concepts.

Keywords: Documentation. Neodocumentacion. Concept of document.

Recebido em 11.06.2018 Aceito em 01.06.2021

\section{Introdução}

No capítulo Exame do estado atual da Biblioteconomia e da Documentação, escrito por Jesse Shera e Margaret Egan, da obra Documentação, de S. C Bradford (1961), os autores afirmam que do encontro de Paul Otlet e Henry La Fontaine nasceu uma série de 
importantes acontecimentos que influenciaram no progresso da documentação por mais de uma geração. Do encontro ocorrido em 1892, surgiu a união dos trabalhos de Otlet e La Fontaine que resultou nos esforços para a criação do Instituto Internacional de Bibliografia e do Repertório Bibliográfico Universal, em 1895 (BRADFORD, 1961; ZAHER, 1968; ORTEGA, 2009). Começou assim a organização da Documentação como corrente teórico-prática e a consolidação de tudo o que foi desenvolvido e conceituado durante esse tempo veio com o lançamento do Traité de documentation, em 1934.

Com seu pensamento visionário, Otlet afirmou que documento é o livro, a revista, o jornal; é a peça de arquivo, a estampa, a fotografia, a medalha, a música; é, também, atualmente, o filme, o disco e toda a parte documental que precede ou sucede a emissão radiofônica (OTLET, 1937, p.1). A visão de Otlet sobre tudo aquilo que poderia ser considerado documento expandiu o conceito para além do livro, do registro escrito, incluindo objetos tridimensionais que também seriam considerados documento. Seu pensamento é considerado um marco originando o movimento documentalista que viria a se ramificar e criar correntes pelos mais diversos países como França, Espanha, Portugal, Estados Unidos entre outros. Suzanne Briet é uma das grandes responsáveis pela continuidade e disseminação da Documentação proposta por Otlet. Bibliotecária e documentalista, em 1951 ela lançou sua obra, Qu'est-ce que la documentation, um manifesto sobre a natureza da documentação, no qual se refere ao documento como uma evidência em apoio de um fato (BUCKLAND, 1998). Briet pensa o documento como evidência baseandose na sua relação indicial com outros documentos e representações documentárias, como registros bibliográficos e metalinguagens, segundo Ronald Day (2001, p.23). O autor acrescenta que apesar de não usar o termo "semiótica", Briet sofreu grande influência de filósofos e linguistas de sua época. Em alinhamento com alguns dos ideais de Otlet, Briet também ampliou a definição de documento, foi além e considerou a possibilidade de seres vivos se tornarem documentos, apresentando seu famoso exemplo do antílope. O animal solto na natureza não pode ser considerado documento. Mas, se fosse capturado, levado para um jardim zoológico e transformado em um objeto de estudo, isto o transformaria em um documento. Tornou-se uma evidência física que está sendo usada por aqueles que a estudam (BUCKLAND, 1997, p.806).

Esses dois conceitos de documento estabelecidos pelos documentalistas clássicos, Otlet e Briet, serviram de base para as diferentes correntes da Documentação que surgiram posteriormente pela Europa. Recentemente redescobertos por pesquisadores em Ciência da Informação as ideias destes dois teóricos franceses reaproximaram a Documentação da Ciência da Informação, em um movimento que 
pretende discutir o documento e a informação, juntamente, para melhor compreensão de suas relações. Alguns pesquisadores nomearam esse movimento de neodocumentação. O objetivo deste estudo é analisar a reaproximação entre a Documentação e a Ciência da Informação a partir deste movimento. Apresenta um breve histórico da Documentação e suas relações com a Ciência da Informação, analisando como essas áreas se afastaram e aponta alguns fatores históricos que contribuíram para sua reaproximação.

\section{A Documentação pelo mundo}

Antes de ser retomada na França nos anos 1960, entre 1940 e 1965, a obra de Otlet caiu no esquecimento, como aponta Ortega (2009, p.64). A documentação voltou a ser foco de interesse com os estudos do Comitê de Ciências da Informação e Comunicação, formado por autores como Robert Escarpit, Jean Meyriat e Roland Barthes. Estes autores trouxeram importantes contribuições não só ao movimento da documentação na França, mas também considerações sobre o desenvolvimento dessa corrente em outros países, a exemplo de Meyriat que em seus textos $(1981,1993)$ discute fatos sobre a terminologia da área e a influência da Documentação na Espanha, como mostram Rabello (2009) e Lund (2009), além das discussões sobre o conceito de documento.

A Espanha tem igual importância na continuidade dos estudos sobre documentação. A documentação como ciência, foi introduzida na Espanha pelas produções de Lasso de La Vega, autor do único Manual de Documentação escrito na Espanha, conforme afirma Lopez Yepes (1995, p.262), em sua obra histórico-conceitual sobre as diversas correntes documentárias, intitulada Teoria de la Documentación, de 1978 e atualizada em 1995, sob o título La Documentación como disciplina: teoria e história (ORTEGA, 2010, p.65). Nessa obra Lopez Yepes aborda a construção epistemológica da documentação, as relações entre biblioteconomia, ciência da informação entre outros tópicos. A corrente espanhola da documentação ainda conta com autores como Sagredo Fernández e Izquierdo Arroyo, Martínez Comeche e o mexicano Réndon Rojas, que enriqueceram os debates sobre o conceito de documento.

No Brasil, Ortega (2009, p.74) considera que a Documentação pode ser descrita por três momentos:

no início do século $X X$, por envolvimento com o projeto do Instituto Internacional de Bibliografia (IIB), a partir dos anos 1940 em movimento que levou à criação do IIB em 1954 até a introdução da corrente estadunidense de Ciência da Informação no Brasil; e a partir dos anos 1980 com o início dos estudos do Grupo Temma, da ECA/USP. 
Juvêncio e Rodrigues (2016) datam a influência da Documentação no Brasil em meados de 1909 quando Manoel Cícero Peregrino da Silva, diretor da Biblioteca Nacional aderiu aos ideais do IIB. Os autores ainda citam outros profissionais que também tiveram importantes participações nessas movimentações, entre eles Victor da Silva Freire, João Augusto dos Santos Porto. Um nome também importante na difusão dos ideais otletianos no Brasil é o de Lydia de Queiroz Sambaquy, bibliotecária que Nanci Odonne (2004) mostrou a importância das iniciativas nos primórdios da Ciência da Informação no Brasil.

Já a adesão à Documentação entre os autores nos Estados Unidos ocorreu mais tarde. Segundo Ortega (2009) o termo Documentação começa a aparecer mais nos Estados Unidos na década de 1950, porém é rapidamente substituído por Biblioteconomia Especializada. Nos Estados Unidos, a Documentação é um termo ligado a Ciência da Informação. Fato, este, que fornece uma primeira impressão sobre o reflexo da Documentação, como movimento teórico, nos países de língua inglesa. Hjorland (2000) se refere à documentação como um termo importante relacionado à Ciência da Informação, citando o biógrafo de Otlet, W. B. Rayward (1975; 1991; 1994). Além de Rayward, outros autores resgataram e traduziram as ideias de Otlet e de Suzanne Briet para o idioma inglês, dentre eles Ronald Day (2006) e Michael Buckland (1995). Essa descoberta ocorreu alguns anos mais tarde do que nos países nos quais já estava consolidada uma tradição documentalista. Esses autores retomaram os conceitos da Documentação clássica e reacenderam os debates acerca da importância de se discutir o documento na Ciência da Informação, para melhor compreensão do seu objeto de estudo, a informação. Quando os estudos sobre o documento pareciam esquecidos e ultrapassados ressurge o questionamento sobre o documento dando formato ao movimento da neodocumentação dentro da Ciência da Informação.

\section{0 retorno ao documento}

Em 1975, W. Boyd Rayward lançou o livro The Universe of Information: the work of Paul Otlet for Documentation and Internacional Organisation, fruto de sua pesquisa como aluno de PhD na Universidade de Chicago, tornando Paul Otlet conhecido na América. Podemos considerar esse como um dos primeiros fatores que contribuíram com o voltar das atenções para a Documentação. Podemos afirmar que do ponto de vista histórico Rayward como biógrafo de Otlet deu o primeiro passo em direção de um movimento que ganharia um contorno mais visível posteriormente. O retorno à questão acerca do documento ocorreu nos níveis conceitual e histórico. No âmbito conceitual, as discussões sobre a natureza do documento e suas relações com a informação ganham força a 
partir da década de 1990. Conceitos como informatividade, documentalidade, materialidade, entre outros são desenvolvidos como suportes para compreender a informação dentro de um novo contexto. No famoso artigo Information as thing, Buckland (1991), apresenta três usos para o termo informação, informação-como-processo, informação-comoconhecimento, informação-como-coisa, pergunta o que é um documento, menciona as ideias de Otlet e Briet, utiliza a noção de Briet sobre o documento em outro artigo, What is a document? (1997), tratando também de aspectos como a semiótica e a antropologia para compreensão do documento. A análise de Buckland sobre informação-como-coisa tem duas consequências importantes: reintroduz o conceito de documento e, por outro lado, indica a natureza subjetiva da informação (CAPURRO; HJORLAND, 2007, p.192). O artigo de Buckland (1991) trouxe definitivamente o conceito de documento de volta às discussões.

Outro pesquisador que deu continuidade às questões conceituais envolvendo documento e informação, adepto de Suzanne Briet, assim como Buckland, é Bernd Frohmann (2004) que em seus estudos afirma que a informatividade dos documentos está sujeita às práticas documentárias, sendo características destas a materialidade, seus lugares institucionais, os modos como são socialmente disciplinadas e sua contingência histórica. Assim como Wittgenstein define o significado pelo uso da linguagem, de maneira análoga, para Frohmann, aquilo que se denomina informação seria o efeito de práticas documentárias (GONZALEZ DE GOMEZ, 2009, p.124)

Em outro artigo, Frohmann (2008) utiliza o pensamento de Foucault sobre a materialidade dos enunciados para ressaltar a importância da materialidade da informação, sem a qual, segundo ele, grande parte das considerações sociais, culturais, políticas e éticas, tão importantes para os estudos da informação, se perdem (FROHMANN, 2008). Frohmann (2009) discute ainda outros conceitos, entre eles, o conceito de documentalidade utilizando o antílope de Briet para guiar a discussão. Frohmann (2009) também revisita a questão colocada por Bukland (1997), sobre o que é documento, indicando que há três motivações filosóficas (instrumental, realista, fundamentalismo de uma filosofia da linguagem) para buscarmos definições. O autor faz algumas considerações baseando-se nas ideias de Stuart Mill e Wittgenstein, sem se comprometer a definir documento. Buckland e Frohmann, quando se trata de questões que relacionam documento e informação, são autores que possuem visibilidade.

Freitas, Marcondes e Rodrigues (2010) sinalizam que nos últimos vinte anos a Ciência da Informação de origem anglo-saxônica redirecionou a questão do documento, em um movimento nomeado mais tarde de Neodocumentação ou Redocumentalização. Niels Lund (2009) afirma que a era pós-moderna está experimentando em larga escala uma re- 
documentação, algo semelhante ao movimento da documentação liderado por Otlet e outros, iniciado há mais de cem anos. Assim com esse novo debate sobre a noção do documento, do seu papel social, da sua relação com a informação, do advento da cultura digital e virtual entre outros aspectos, esses pesquisadores que traduziram as obras dos documentalistas clássicos, deram os primeiros passos para a projeção do movimento neodocumentalista, fazendo com que a Ciência da Informação e a Documentação retomassem o diálogo para melhor compreensão da informação registrada, ou seja, do documento. Podem ser reconhecidos assim, os primeiros sinais de uma nova tendência da Documentação na Ciência da Informação. Mostafa (2011, p.13) afirma que o nome de Suzanne Briet estará, na América, sempre ligado ao de Ronald Day, que foi quem a traduziu e ao de Michael Buckland, seu biográfo, e são recentes ambas as iniciativas. Ortega (2009) reforça que apesar das contribuições significativas dos autores franceses, os pesquisadores da Ciência da Informação americana parecem ignorar os trabalhos daqueles pesquisadores, reconhecendo apenas a importância dos pioneiros Otlet e Briet. O que nos ajuda a compreender a visibilidade de autores como Rayward, Frohmann e Buckland, assim como o envolvimento dos pesquisadores americanos com o assunto.

Foi por meio do resgate das ideias de Otlet por W. Boyd Rayward que Buckland se interessou pelo trabalho dos documentalistas europeus do século $X X$ e se reuniu em outro momento com Niels Lund para organizar o que os próprios autores definem como uma agenda neodocumentalista que resultou em uma rede informal internacional de pesquisa, The Document Academy ${ }^{1}$ (BUCKLAND; LUND, 2008).

Então, retornar ao conceito de documento se configura como uma orientação para a melhor compreensão da informação registrada, em especial, no ambiente digital/virtual. Contudo, Freitas (2010) adverte que nem sempre fica entendido que a motivação para esse movimento, de retorno, se origina de bases diferenciadas. A autora propõe as seguintes subdivisões para a produção sobre o tema:

Abordagens pragmáticas ou operacionais: esforços conceituais de sistematização dos objetos que efetivamnete vêm sendo socialmente produzidos ou mobilizados como documento e considerados como veículos de informações socialmente relevantes; Abordagens filósoficas ou epistemológicas: esforços teóricos, analíticos e críticos tanto dos usos socio-históricos que produzem e mobilizam objetos como documento, quanto dos esforços conceitual-pragmáticos de sistematização sobre tais objetos (FREITAS, 2012, p.145).

\footnotetext{
${ }^{1}$ The Document Academy : < http://documentacademy.org/>.
} 
$\mathrm{Na}$ primeira abordagem a preocupação refere-se as atividades documentárias que envolvem os documentos e seu uso social, em uma preocução de como lidar com esses objetos. Na segunda observa-se a intenção em compreender, por meio de questionamentos filosóficos, qual a atuação social e cultural do documento em seu contexto histórico. Há na Ciência da Informação um momento de questionamentos sobre a abordagem do seu objeto já que ele sofreu modificações ao longo do seu percurso, em uma transição do paradigma da Ciência da Informação que nasceu em meados do século XX com um paradigma físico, questionado por um enfoque cognitivo idealista e individualista, sendo substituído por um paradigma pragmático e social, como sugere Capurro (2007, p.13). Nota-se então a necessidade que houve, e há, de repensar a informação, que já fora considerada um fenômeno físico, depois um fenômeno cognitivo individual, e agora é analisada como uma possível construção de suas relações sociais.

Há então o resgate da discussão sobre a constituição do conceito de documento para se repensar o conceito de informação, refletindo nas discussões atuais dentro da Ciência da Informação essa tendência documentalista. Vale ressaltar que as correntes espanhola e francesa possuem uma forte e consolidada tradição documentalista, como mostram Lopez Yepes (1995); Lund (2009); Ortega (2009) entre outros. São pesquisadores dos Estados Unidos, Canadá entre outros, que somente anos mais tarde, buscam referências nos trabalhos de Otlet e Briet, iniciando o que podemos chamar de uma reaproximação conceitual atual entre Documentação e Ciência da Informação. Buckland (2013) afirma que após a década de 1940, a Documentação foi amplamente deixada de lado até que o interesse sobre a mesma foi reavivado na década de 1990 .

Esse movimento voltando as atenções novamente para o documento surge da premissa de que a Documentação entre alguns pesquisadores, principalmente nos Estados Unidos, não teve a força que teve nos outros países, como os já citados Espanha e França por exemplo, tendo seu desenvolvimento tardio, porém para esses autores do mundo anglosaxão, constata-se a continuidade e atualização da versão clássica da noção de documento (LARA; ORTEGA, 2012, p.377). Os fatos nos remetem ao início do século XX, por volta da década de 1920, quando bibliotecários e documentalistas começaram a diferenciar os seus interesses profissionais, levando a uma divisão da abordagem conceitual.

Nos Estados Unidos, por exemplo, dentre os motivos situam-se escolhas e interesses tanto de cárater pragmático quanto conceitual, que guiam e levam a caminhos diferentes a Documentação e a Biblioteconomia, resultando mais à frente na Ciência da Informação, que carrega consigo os resultados desse caminho bifurcado. Pensando na 
dimensão histórica, Buckland (2002) sugere que na década de 1930 a Graduate Library School of Chicago, também conhecida como "a Escola de Chicago" e os documentalistas europeus representavam duas escolas de pensamento diferentes, fato este, que após a Segunda Guerra Mundial, foi reforçado, quando a tradição norte-americana voltou seu interesse para a tecnologia. Segundo o autor citado, houve um espaço de vinte anos para que as questões abordadas pelos documentalistas europeus ganhassem espaço na biblioteconomia. Assim também na Grã-Bretanha, por uma fissura das questões profissionais, a dissociação entre documentalistas e bibliotecários é surpreendentemente semelhante à que ocorreu nos Estados Unidos (EGAN; SHERA, 1953, p.32). Tratam-se de escolhas conceituais nas organizações relacionadas a essas áreas do conhecimento que resultaram na maior influência de uma sobre a outra ou então na exclusão dos seus ideais. Fato este que reflete nas configurações da Ciência da Informação como a conhecemos, dando também abertura para que nesse período, dentre as discussões acerca do seu objeto de estudo a informação registrada - surgisse espaço para o diálogo com a Documentação, esta área que para muitos era um assunto superado e ultrapassado.

\section{Considerações finais}

Existe uma tendência de pensamento que nas últimas duas décadas reacendeu a discussão sobre a natureza do documento. $\mathrm{O}$ movimento com uma percepção documentalista não apenas "redescobriu" as ideias de Paul Otlet, mas impulsionou as questões já existentes na Documentação mostrando que, é necessário não apenas se pensar o documento, mas as relações existentes entre o documento e a informação para compreender as novas configurações dos registros da informação. Não há uma razão para se ocupar do conceito de informação em detrimento do conceito de documento. A noção de documento pode ser pensada como uma forma de recapitular as variabilidades e ambiguidades que caracterizam a noção de informação, segundo Rayward (1996, p.5). Os debates sobre a natureza, as aplicações e os entendimentos sobre o documento se mostram ricos com muitas contribuições para as áreas que dele se ocupam como a Biblioteconomia, por exemplo, correlata tanto à Ciência da Informação quanto a Documentação.

Não se trata apenas da busca por uma definição do documento, é uma discussão que influencia a forma de se pensar e trabalhar a informação registrada. Há espaço e interesse para se pensar sobre o conceito de documento em Ciência da Informação sob a perspectiva da Documentação. Pinheiro (2013) relata que a partir dos anos 1990 a sociedade da informação vivenciou uma nova explosão informacional, devido ao surgimento das novas tecnologias e configurações de novas 
problemáticas. Nessa nova e mais arrebatadora "explosão da informação", chama atenção a intensidade das pesquisas de antigas questões (PINHEIRO, 2013, p.26). E nesse contexto, no qual as ideias da Documentação foram retomadas por pesquisadores em Ciência da Informação tornam-se muito importante as pesquisas sobre o documento, esse conceito que muito tem para contribuir com a compreensão acerca da informação, esse objeto de estudo que está sempre em constante transformação.

\section{Referências}

BRADFORD, S. C. Documentação. Rio de Janeiro: Fundo de Cultura, 1961. $292 \mathrm{p}$.

BUCKLAND, M. Document Theory: an introduction. in: Conference and School on records, archives and memory studies, 2013. Records, Archives and Memory: selected papers. Croácia: Universidade do Zadar, maio, 2013. p.223-237.

BUCKLAND, M. Information as thing. JASIS, v. 42, n. 5, p.351-36,1991. Disponível em: http://people.ischool. berkeley.edu/ buckland/thing.html. Acesso em: 04 jun. 2018.

BUCKLAND, M. What is a document? JASIS, v.48, n. 9, p.804-809, 1997. Disponível em:

http://people.ischool.berkeley.edu/ buckland/whatdoc.html. Acesso em: 04 jun. 2018.

BUCKLAND, M.; LUND, N.W. Document, documentation, and the Document Academy: introduction. Arch Sci, n.8, p.161-164, 2008.

CAPURRO, R. Epistemología y Ciencia de la Información. Enl@ace: Revista Venezolana de Información, Tecnología y Conocimiento, v. 4, n. 1, EneroAbril, p.11-29, 2007. Disponível em:

http://www.redalyc.org/articulo.0a?id=82340102. Acesso em: 04 jun. 2018.

CAPURRO, R.; HJØRLAND, B. O conceito de informação. Perspec. Ci. Inf., Belo Horizonte, v.12, n.1, p. 148-207, abr. 2007. Disponível em: http://bogliolo.eci.ufmg.br/downloads/CAPURRO.pdf. Acesso em: 04 jun. 2018.

DAY, R. The modern invention of Information : discourse, history, and power. Carbondale: Southern Illinois University Press, 2008. 139 p. Disponível em: 
https://monoskop.org/images/9/92/Day Ronald E Modern_Invention of Information Discourse History and Power.pdf. Acesso em: 04 jun. 2018.

FREITAS, L.S. O dispositivo de arquivo: a construção histórico-discursiva do documento e do fato. In: FREITAS, L.S.; MARCONDES, C.H.; RODRIGUES, A.C. (Org.) Documento: gênese e contextos de uso. Rio de Janeiro: Editora da UFF, 2010.

FREITAS, L.S.; MARCONDES, C.H.; RODRIGUES, A.C. (Org.) Documento: gênese e contextos de uso. Rio de Janeiro: Editora da UFF, 2010.

FROHMANN, B. O caráter social, material e público da informação. In: FUJITA, M.; MARTELETO, R.; LARA, M. (Org.). A dimensão epistemológica da ciência da informação e suas interfaces técnicas, políticas e institucionais nos processos de produção, acesso e disseminação da informação. São Paulo: Cultura Acadêmica; Marília: Fundepe, 2008, p. 1934. Disponível em:

http://repositorios.questoesemrede.uff.br/repositorios/handle/123456789 1829. Acesso em: 04 jun. 2018.

FROHMANN, B. Revisiting "what is a document?", Journal of Documentation, v.65 , n.2, p.291-303, 2009. Disponível em: http://www.emeraldinsight.com/doi/full/10.1108/00220410910937624. Acesso em: 04 jun. 2018.

GONZALEZ DE GOMEZ, M.N. A reinvenção contemporânea da informação: entre o material e o imaterial. Pesq. bras. Ci. Inf., Brasília, v.2, n.1, p.115-134, jan./dez. 2009. . Disponível em:

http://repositorio.ibict.br/bitstream/123456789/116/1/GonzalezGomezTe ndencias2009.pdf. Acesso em: 04 jun. 2018.

HJØRLAND, B. Documents, memory institutions and information science. Journal of Documentation, v. 56, n.1, p. 27 - 41, 2000. Disponível em: http://www.emeraldinsight.com/doi/abs/10.1108/EUM0000000007107. Acesso em: 04 jun. 2018.

JUVÊNCIO, C. H.; RODRIGUES, G. M. A documentação no Brasil: primórdios de sua inserção no país (1895-1920). Revista Ibero-Americana de Ciência da Informação, [S.I.], v. 9, n. 1, p. 271-284, nov. 2015. ISSN 1983-5213. Disponível em: http://periodicos.unb.br/index.php/RICI/article/view/16958. Acesso em: 04 jun. 2018.

LARA, M. L.G.; ORTEGA, C.D. Para uma abordagem contemporânea do documento na Ciência da Informação. In: X CONGRESSO ISKO CAPÍTULO 
ESPAÑOL, 2011. 20 Años del Capítulo Español de ISKO. Actas del... Ferrol: Universidade da Coruña, 2012. p. 371-387

LOPEZ YEPES, J. La documentación como disciplina: teoria e história. 2. ed. actual. y ampl. Pamplona: EUNSA, 1995.

LUND, N. W. Document theory. Annual Review of Information Science and Technology, v. 43, p. 399-4321, 2009.

ODONNE, N. Ciência da informação em perspectiva histórica: Lydia de Queiroz Sambaquy e o aporte da Documentação (Brasil, 1930-1970). 2004. $161 \mathrm{f}$. Tese (Doutorado) - Universidade Federal do Rio de Janeiro / Instituto Brasileiro de Informação em Ciência e Tecnologia, Rio de Janeiro, 2004. Disponível em:

http://ridi.ibict.br/bitstream/123456789/691/1/oddone2004.pdf. Acesso em: 04 jun. 2018.

ORTEGA, C.D. Sobre a configuração histórica da noção de documento em Ciência da Informação. In: FREITAS, L.S.; MARCONDES, C.H. ; RODRIGUES, A.C. (Org.) Documento: gênese e contextos de uso. Rio de Janeiro: Editora da UFF, 2010.

ORTEGA, C.D. Surgimento e consolidação da Documentação: subsídios para compreensão da história da Ciência da Informação no Brasil.

Perspec. Ci. Inf., v. 14, p. 59-79, 2009. Disponível em:

http://www2.marilia.unesp.br/revistas/index.php/bjis/article/viewFile/48/ 263. Acesso em: 04 jun. 2018.

OTLET, P. Documentos e documentação: discurso pronunciado no Congresso de Documentação Universal, Paris, 1937. Rio de Janeiro: Imprensa Nacional (Separata). Disponível em: http://www.conexaorio.com/biti/otlet/. Acesso em: 04 jun. 2018.

PINHEIRO, L.V.R. Fronteiras e horizontes da pesquisa em Ciência da Informação no Brasil. In: ALBAGLI, Sarita. (Org.). Fronteiras da Ciência da Informação.Brasília: IBICT, 2013, v. 1.

RAYWARD, W.B. The history and historiography of information science: Some reflections. Information Processing \& Management, v. 32, n.1, p.3$17,1996$.

SHERA, J.; EGAN, M. Exame do estado atual da Biblioteconomia e da Documentação. In: BRADFORD, S. C. Documentação. Rio de Janeiro: Fundo de Cultura, 1961. 292 p.

ZAHER, C. R. Introdução à documentação. 2. ed. Rio de Janeiro: [s.n.], 1968. 174 p. 